\section{EMBRYRIDDLE \\ Aeronautical University}

SCHOLARLY COMMONS

\section{International Journal of Aviation,} Aeronautics, and Aerospace

\title{
Assessing Situation Awareness in Unmanned Aircraft Systems Operations
}

Haydee M. Cuevas

Embry-Riddle Aeronautical University - Daytona Beach, cuevash1@erau.edu

Marisa Aguiar

Embry-Riddle Aeronautical University, aguiarm@my.erau.edu

Follow this and additional works at: https://commons.erau.edu/ijaaa

Part of the Aviation Safety and Security Commons

\section{Scholarly Commons Citation}

Cuevas, H. M., \& Aguiar, M. (2017). Assessing Situation Awareness in Unmanned Aircraft Systems Operations. International Journal of Aviation, Aeronautics, and Aerospace, 4(4). https://doi.org/10.15394/ ijaaa.2017.1176

This Article is brought to you for free and open access by the Journals at Scholarly Commons. It has been accepted for inclusion in International Journal of Aviation, Aeronautics, and Aerospace by an authorized administrator of Scholarly Commons. For more information, please contact commons@erau.edu. 


\section{Assessing Situation Awareness in Unmanned Aircraft Systems Operations}

\section{Cover Page Footnote}

Acknowledgments This research was partially supported by funding from FY14 ERAU Faculty Internal Research Grant \#13208 to the first author. The views herein are those of the authors and do not necessarily reflect those of the organization with which the authors are affiliated. Portions of this paper were presented at the 18th International Symposium on Aviation Psychology. Special thanks to the following individuals for their valuable contributions to this research: Kristina Kendrick, Zane Ziegler, David Hamilton, Alex Mirot, Dat Nghiem, and Shane Thompson. 
This paper reports a study aimed at conducting an initial evaluation of a behavioral measure for assessing situation awareness (SA) in unmanned aircraft systems (UAS) operations. This SA behavioral measure was used to evaluate how specific operator characteristics (knowledge, skills, and abilities or KSAs) influence mission success in UAS operations. Greater experience in the targeted KSAs (prior experience in manned and unmanned flight, teamwork, and gaming) was hypothesized to be positively correlated with a better indication of SA behaviors during a simulated UAS scenario.

This paper begins with a brief discussion of the SA construct and its measurement, followed by a detailed review of the SA behavioral measure investigated in the study. Challenges faced in UAS operations are also highlighted to provide a context for the study. The method and results of the study are then described. The paper concludes with implications for practice.

\section{Literature Review}

\section{Situation Awareness and its Measurement}

Situation awareness has been defined as "the perception of the elements in the environment within a volume of time and space, the comprehension of their meaning and the projection of their status in the near future" (Endsley, 1995, p. 36). SA has been recognized as a critical, yet often elusive, foundation for successful decision-making across a broad range of complex and dynamic systems, including aviation and air traffic control (e.g., Nullmeyer, Stella, Montijo, \& Harden 2005), emergency response and military command and control operations (e.g., Blandford \& Wong 2004; Gorman, Cooke, \& Winner 2006; Wills, 2011), and offshore oil and nuclear power plant management (e.g., Flin \& O’Connor, 2001).

While the SA construct has been widely researched due to its vast range of application, the multivariate nature of SA poses a considerable challenge to its quantification and measurement (for a detailed discussion on SA measurement, see Breton, Tremblay, \& Bandbury, 2007; Endsley \& Garland, 2000; Fracker, 1991a; 1991b). Yet, measuring SA provides valuable information with greater sensitivity than simply measuring standard performance outcomes. In addition, measuring SA allows for evaluation of a system design to ensure the previously set goals are being met as well as to establish a baseline for comparing the effects of training and system design (Bolstad, Cuevas, Wang-Costello, Endsley, \& Angell, 2010; Stanton, Salmon, Walker, Salas, \& Hancock, 2017). 


\section{Situation Awareness Linked Indicators Adapted to Novel Tasks (SALIANT)}

In dynamic, high-tempo operations, SA should be assessed using measures that do not disrupt task performance. Behavioral measures 'infer' SA from the actions individuals choose to take, based on the assumption that good actions will follow from good SA and vice versa. The Situation Awareness Linked Indicators Adapted to Novel Tasks (SALIANT) methodology, developed by Muniz, Stout, Bowers, and Salas (1998), provides a theoretically-based assessment of the observed behaviors indicative of the team process behaviors that support the team's situation awareness (e.g., how information exchange is used as an input for building team member SA; Milham, Barnett, \& Oser, 2000). Specifically, these general indicators are used to identify how observable group behaviors are employed in the operational environment and to detect any relevant issues that may lead to potential breakdowns in SA. What distinguishes SALIANT from other behavioral measures is its focus on team-level SA behaviors, that is, SALIANT attempts to capture SA in a team setting.

Multiple validation studies have reported the usefulness of SALIANT. The SALIANT methodology has demonstrated a high level of adaptability as it can be used in both field trial experiments and simulator environments (SESAR, 2012). For example, SALIANT has been successfully validated for distributed Army teams, cockpit navigators, and using highly structured training scenarios within a low-fidelity simulation (e.g., Milham et al., 2000; Muniz et al., 1998). Fink and Major (2000) found that SALIANT had better psychometric properties than two other SA measures, the Situational Awareness Probe Technique (SAP) and the Situational Awareness Rating Technique (SART). In their review of the psychometric properties of available measurement tools, Breton et al. (2007) indicated SALIANT had solid inter-rater reliability and a good correlation with performance (predictive validity).

The SALIANT methodology involves creating an event-based behavioral checklist that links specific instances of behaviors to targeted SA indicators. This checklist can then be used to evaluate how successfully these observable SA behaviors are employed in the operational environment. The 16 SALIANT behavioral indicators, as originally identified by Muniz et al. (1998), are listed below:

1. Demonstrates awareness of location in space

2. Uses available information sources

3. Briefs status

4. Provides information in advance

5. Informs others of actions taken 
6. Cross checks information

7. Demonstrates knowledge of tasks

8. Provides and requests backup

9. Exhibits skilled time sharing among tasks

10. Scans internal and external environment for abnormal conditions, changes, landmarks

11. Anticipates consequences of actions, decisions, and potential problem situations

12. Takes action at the appropriate time

13. Reports problems

14. Locates potential source of problem

15. Resolves discrepancies

16. Adheres to standard communication format

These 16 indicators can be further organized into five general categories based on how these behaviors are related (for a detailed description of this categorization process, see Fiore, Fowlkes, Martin-Milham, \& Oser, 2000), as shown in Table 1. The continuous SA behaviors in the checklist are further classified as either associated with quantitative or qualitative evaluations, as determined by trained observers. A value is assigned to each observer rating, which can then be tagged to the targeted SA behavior. These values can be utilized to calculate the team's SA in a given mission phase.

\section{Challenges in Unmanned Aircraft Systems Operations}

The use of unmanned aircraft systems is increasing at an unprecedented pace, with a broad range of applications including oil and gas exploration, agricultural management, wildfire mapping, weather monitoring, and emergency response (AUVSI, 2013). This trend has created significant human performance challenges such as how to: select and train UAS operators; design UAS control interfaces to minimize errors and avoid costly accidents; and safely integrate UAS into the National Airspace System (e.g., Dalamagkidis, Valavanis, \& Piegl, 2008; Williams, 2006). The problems associated with these challenges are many, yet the solutions are presently few (Fern, Shively, Draper, Cooke, \& Miller, 2011). Also, UAS crews differ from manned flight crews in crucial ways: crew and aircraft are not co-located; shift changeovers may occur during a mission; crew may be tasked to control multiple aircraft; monitoring and feedback latency is common; lack standardized cockpit design and controls; lack standardized crew qualifications; and lack 'shared fate' with the aircraft (Tvaryanas, 2006). Research is critically warranted to investigate these challenges, and useful SA measures are required to support these endeavors. 
Table 1

Categorization of SALIANT Indicators (adapted from Fiore et al., 2000)

\begin{tabular}{ll}
\hline SA Category & SALIANT Indicator \\
\hline 1. Spatial Orientation & 1.1 Demonstrates awareness of location in space \\
& 1.2 Uses available information sources \\
& 1.3 Cross checks information \\
1.4 Scans internal and external environment for abnormal & conditions, changes, landmarks \\
& 2.1 Provides and requests backup \\
& 2.2 Reports problems \\
2. Cue Sharing & 2.3 Informs others of actions taken \\
& 3.1 Locates potential source of problem \\
3. Problem Solving & 3.3 Anticipates consequences of actions, decisions, and \\
& potential problem situations \\
& 4.1 Provides information in advance \\
& 4.2 Adheres to standard communication format \\
4.Information Managements & 4.3 Briefs status \\
& 5.1 Takes action at the appropriate time \\
5. Task Management & 5.3 Exhibits skilled time sharing among tasks \\
\hline
\end{tabular}

\section{Development of a UAS Taxonomy}

A necessary first step in this study involved identifying the factors that influence UAS operator mission success. A review was conducted of the extant scientific literature and relevant FAA and military technical reports. Findings from this review were organized into a theoretically-based UAS Taxonomy that lists each factor, a basic definition of the factor, and its hypothesized effect on UAS operator performance, supported with citations from relevant literature. Representative examples of the factors identified in the UAS Taxonomy are listed in Table 2.

A prioritized subset of these factors was selected from the UAS Taxonomy for this initial study. The primary selection criteria were the factor's hypothesized influence on UAS operator SA and the extent to which the factor was amenable to training and assessment. The factors selected were flight skill in manned and unmanned flight environments, teamwork experience, and gaming experience. 
Table 2

Representative Examples of Factors from UAS Taxonomy

\begin{tabular}{|c|c|c|c|c|}
\hline Knowledge & Skills & Abilities & Task Env & Sit'l \\
\hline $\begin{array}{l}\text { - team } \\
\text { leadership }\end{array}$ & - flight skill & $\begin{array}{l}\text { - instrument } \\
\text { monitoring }\end{array}$ & $\begin{array}{l}\text { - } \text { team } \\
\text { composition }\end{array}$ & $\begin{array}{l}\text { - human } \\
\text { locations }\end{array}$ \\
\hline - delegation & - target search & $\begin{array}{l}\text { - mission } \\
\text { monitoring }\end{array}$ & - culture & $\begin{array}{l}\text { - } \text { human } \\
\text { activities }\end{array}$ \\
\hline $\begin{array}{l}\text { - commander's } \\
\text { intent }\end{array}$ & - navigation & $\begin{array}{l}\text { - long-term } \\
\text { monitoring }\end{array}$ & - workload & $\begin{array}{l}\text { - human } \\
\text { activity } \\
\text { dependen- } \\
\text { cies }\end{array}$ \\
\hline $\begin{array}{l}\text { - mission } \\
\text { awareness }\end{array}$ & $\begin{array}{l}\text { - mission } \\
\text { planning / } \\
\text { replanning }\end{array}$ & $\begin{array}{l}\text { - } \text { risk } \\
\text { perception }\end{array}$ & - fatigue & $\begin{array}{l}\text { - human } \\
\text { character- } \\
\text { istics }\end{array}$ \\
\hline $\begin{array}{l}\text { - } \text { plan } \\
\text { understanding } \\
\text { - shared } \\
\text { situation } \\
\text { awareness }\end{array}$ & 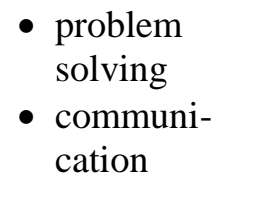 & $\begin{array}{l}\text { - risk-taking } \\
\text { behavior } \\
\text { - risk manage- } \\
\text { ment }\end{array}$ & $\begin{array}{l}\text { - information } \\
\text { overload } \\
\text { - distraction }\end{array}$ & $\begin{array}{l}\text { - human } \\
\text { identities } \\
\text { - human } \\
\text { intentions }\end{array}$ \\
\hline $\begin{array}{l}\text { - shared mental } \\
\text { models }\end{array}$ & $\begin{array}{l}\text { - teamwork } \\
\text { skills }\end{array}$ & $\begin{array}{l}\text { - contingency } \\
\text { behavior }\end{array}$ & - stress & \\
\hline
\end{tabular}

Note $:$ Task Env = Task Environment; Sit'1 = Situational

\section{Method}

\section{Participants}

Eighteen participants (all males) ranging from 21 to 45 years $(M=25.29$; $S D=6.95$ ) participated in this study as part of two-person crews (pilot, sensor operator). Participants were recruited from the Unmanned Aircraft Systems Science (UASS) undergraduate program at a private aeronautical university in the southeastern United States. The UASS degree provides the necessary expertise for graduates to seek employment as pilots/operators, observers, sensor operators, and operations administrators of UAS. Thus, recruiting participants from this subject pool help to increase the generalizability of the study's findings to real-world UAS operations. Participants were either currently enrolled or had recently completed the UAS Flight Simulation course, the final capstone course in the UASS program. One crew was dropped from the analysis due to missing data, leaving a total of eight two-person crews. All participants in the study were treated in accordance with the ethical standards of the American Psychological Association. The study 
protocol was reviewed and approved by the university's Institutional Review Board.

\section{Materials and Procedure}

The study was conducted in the university's UAS Laboratory. The UAS Laboratory features 8 Tactical Unmanned Aerial System (X-TUAS ${ }^{\mathrm{TM}}$ ) training devices (URS Corp.) that can be operated as 8 dual-station or 16 single-station systems. The simulators are designed and built around proven image generator software for real-time control and rendering of medium-wave electro-optical (EO) and infrared (IR) sensor views together with controls, displays, and a 2D tactical map for air vehicle operations. The X-TUAS ${ }^{\text {TM }}$ simulators accurately and with high fidelity represent the ground control station (GCS) hardware and flight characteristics of mid-sized medium altitude, long endurance (MALE) unmanned aerial vehicles. Each of the 16 networked workstations can simulate either a pilot or sensor operator station and can be linked to simulate a full crew station as shown in Figure 1.

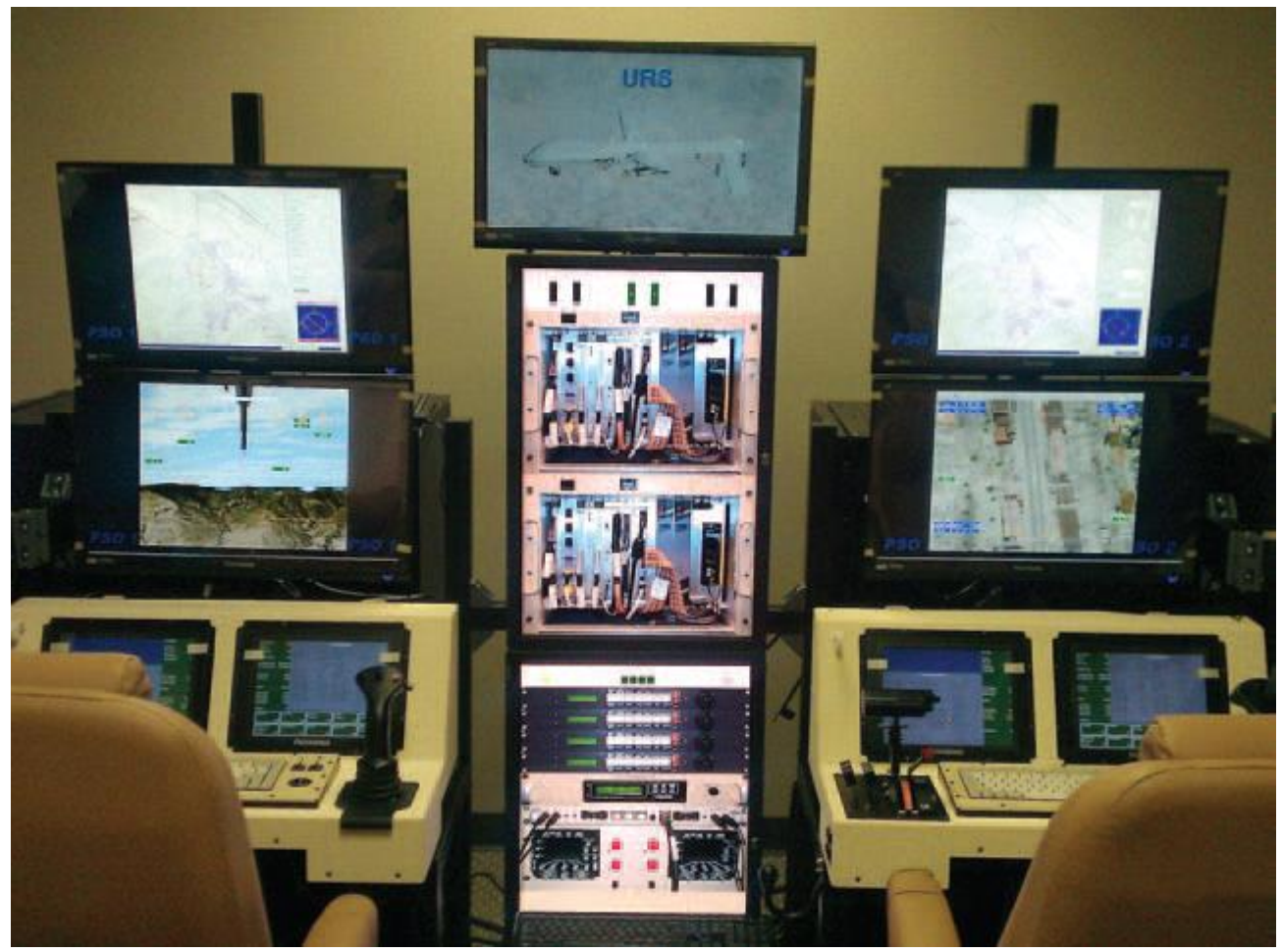

Figure 1. X-TUAS ${ }^{\mathrm{TM}}$ simulators in the full crew (pilot and sensor operator) station configuration (Source: http://www.urs-simulation.com). 
Prior to participation in the study, participants were asked to review and complete an informed consent form and a Prior Experience Questionnaire. The purpose of the Prior Experience Questionnaire was to collect information on the targeted KSAs. Table 3 lists the items surveyed on the Prior Experience Questionnaire.

To assess the influence of these KSAs on team SA, the study leveraged an existing UAS scenario (port security) developed for the UAS Flight Simulation course. In the port security scenario, the UAS crew (pilot and sensor operator) must navigate the UAS to a designated location in the harbor, conduct surveillance in the area to detect and identify the targeted vessel, gather information on the vessel, and then return the UAS to base. During each scenario, crews were presented with an emergency (e.g., oil leak, engine failure) requiring dynamic replanning and teamwork to resolve the situation.

In consultation with the course instructor, two subject matter experts (SMEs) created a modified version of the SALIANT methodology that included three new categories (see Table 4). The two SMEs had extensive experience with the UAS simulator and the UAS scenario. The two SMEs carefully reviewed the UAS scenario and then mapped the naturally occurring team behaviors associated with the SALIANT indicators onto a chronological checklist based on expectations of how these behaviors would unfold during the course of the scenario. Examples of SALIANT checklist items are shown in Table 5. For the study, two additional SMEs, also experienced with the UAS simulator and the UAS scenario, were trained on the use of the SALIANT checklist. During completion of the UAS scenario, the four SMEs completed the SALIANT checklist, with two trained observers per crew. Following each session, raters conferred to achieve consensus on the ratings.

\section{Results and Discussion}

Given the small sample size and directional hypothesis for this initial study, alpha was set at $p<.05$, one-tailed. As illustrated in Table 6, the SALIANT indicators were able to discriminate differences in SA behaviors among the eight crews. Scores across the SALIANT categories ranged from a minimum of $0 \%$ to a maximum of $100 \%$. Average scores ranged from $28 \%$ to $58 \%$. 
Table 3

Prior Experience Questionnaire Assessing Targeted KSAs

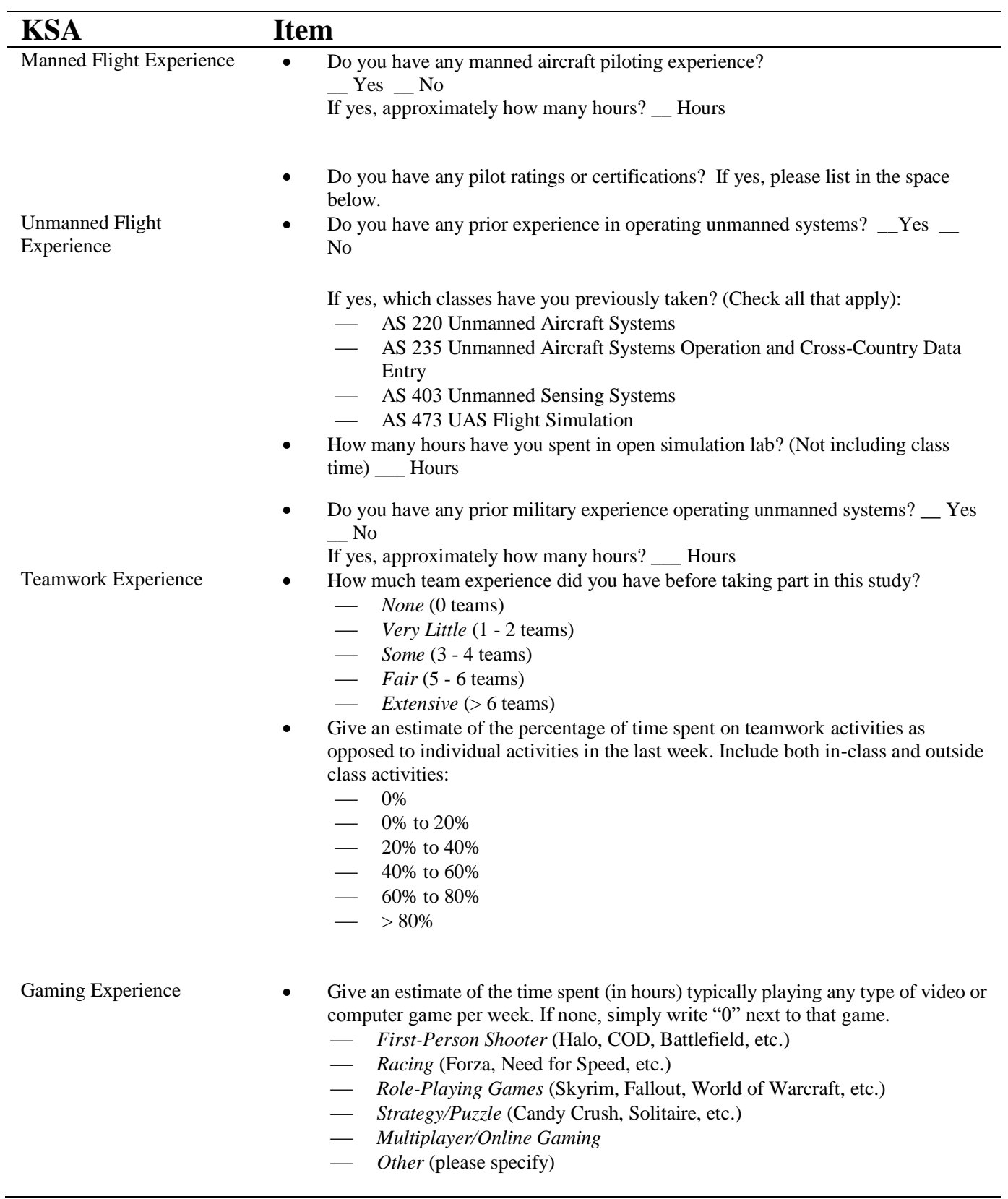

Note: Responses listed for the pilot ratings or certifications question included: none $(n=$ $10)$; private $(n=4)$; private, instrument $(n=0)$; commercial, AMEL, instrument $(n=2)$. 
Table 4

Modified SALIANT Indicators

\begin{tabular}{ll}
\hline Category & SALIANT Indicator \\
\hline 6. Task / Equipment & 6.1 Demonstrates knowledge of tasks \\
Knowledge & 6.2 Demonstrates knowledge of equipment/systems \\
& 6.3 Commits minimal operational errors and \\
& mistakes \\
7. Crew Resource & 7.1 Resolves conflicts with teammates \\
Management & 7.2 Delegates tasks with appropriate feedback \\
& 7.3 Asks clarification questions as necessary \\
8. Mission Monitoring & 7.4 Effectively use available resources \\
& 8.1 Engages in mission planning and dynamic re- \\
& planning \\
& 8.2 Recognizes and responds to messages sent to \\
& crew \\
\hline
\end{tabular}

Table 5

Example SALIANT Checklist Items for Port Security UAS Scenario

\begin{tabular}{lll}
\hline Category & SALIANT Indicator & Checklist Item \\
\hline Spatial Orientation & $\begin{array}{l}\text { Demonstrates awareness of } \\
\text { location in space }\end{array}$ & $\begin{array}{l}\text { Pilot raises landing gear at } \\
\text { appropriate altitude }\end{array}$ \\
Crew Resource & $\begin{array}{l}\text { Delegates tasks with } \\
\text { appropriate feedback }\end{array}$ & $\begin{array}{l}\text { Crew works together to } \\
\text { identify emergency }\end{array}$ \\
Mission & $\begin{array}{l}\text { Engages in mission } \\
\text { planning and dynamic } \\
\text { Monitoring }\end{array}$ & $\begin{array}{l}\text { Pilot continually updates } \\
\text { the emergency mission } \\
\text { replanning }\end{array}$ \\
\hline
\end{tabular}


Table 6

Descriptive Statistics for SALIANT Categories

\begin{tabular}{lllll}
\hline SALIANT Category & Min & Max & Mean & Std Dev \\
\hline Spatial Orientation & .4188 & .8182 & .5490 & .1351 \\
Cue Sharing & .3281 & .8438 & .5800 & .1607 \\
Problem Solving & .0000 & .7500 & .2813 & .2720 \\
Information & .0833 & .7167 & .3177 & .2229 \\
Management & & & & \\
Task Management & .0000 & 1.0000 & .5158 & .2615 \\
Crew Resource & .2500 & 1.0000 & .5313 & .3010 \\
Management & & & & \\
\hline
\end{tabular}

Note $. \mathrm{N}=16$ for each category. Min = Minimum; Max = Maximum; Std Dev = Standard Deviation.

Bivariate correlation analysis was conducted between each of the targeted KSAs (flight experience, teamwork experience, and gaming experience) and SA behaviors as assessed by the SALIANT. Statistically significant correlations between the KSAs and SALIANT categories are reported in Table 7. No other correlations between the KSAs and SALIANT indicators were statistically significant. Thus, the study hypothesis was only partially supported.

Table 7

Statistically Significant Correlations between KSAs and SALIANT Categories

\begin{tabular}{|c|c|c|}
\hline KSA & SALIANT Category & Correlation \\
\hline \multicolumn{3}{|l|}{ Manned Flight Experience } \\
\hline Manned Aircraft Piloting & Crew Resource & $r(16)=.557, p=.0125$ \\
\hline Experience & Management & \\
\hline Manned Flying Hours & $\begin{array}{l}\text { Crew Resource } \\
\text { Management }\end{array}$ & $r(15)=.542, p=.0185$ \\
\hline Pilot Ratings / & Crew Resource & $r(16)=.473, p=.032$ \\
\hline Certifications & Management & \\
\hline \multicolumn{3}{|l|}{ Teamwork Experience } \\
\hline Team Experience & Task Management & $r(16)=.471, p=.0325$ \\
\hline Team Experience & Problem Solving & $r(16)=.471, p=.033$ \\
\hline Team vs. Individual \% & Problem Solving & $r(16)=.465, p=.035$ \\
\hline \multicolumn{3}{|l|}{ Gaming Experience } \\
\hline First-Person Shooter & Spatial Orientation & $r(16)=.503, p=.0235$ \\
\hline
\end{tabular}


Results showed a statistically significant positive correlation between Manned Flight Experience and SALIANT indicators for Crew Resource Management (CRM). Participants with greater Manned Flight Experience performed better on the SALIANT CRM items. This result is to be expected since pilots receive CRM training during the course of their flight instruction.

Results also showed a statistically significant positive correlation between Teamwork Experience and SALIANT indicators for Task Management and Problem Solving. Participants with greater Teamwork Experience performed better on the SALIANT Task Management and Problem Solving items. This finding suggests that crews were able to transfer domain-general team KSAs to coordinate their activities while completing the UAS scenario.

Finally, results showed a statistically significant positive correlation between Gaming Experience with First-Person Shooter games and SALIANT indicators for Spatial Orientation. Participants with greater experience with these types of games performed better on the SALIANT Spatial Orientation items. This result likely may be due to the requirement for spatial awareness in these kinds of games where the player is an avatar in a virtual world. In order to succeed, the player must take in all available information to assess their situation correctly.

\section{Study Limitations}

Results from this initial study offer some support for the potential utility of the SALIANT methodology as an SA assessment tool in UAS operations. However, while promising, conclusions drawn from these results are tentative due to the study's limitations. First, the study's sample size was limited by the small class sizes for the UAS Flight Simulation course from which the participants were recruited. Although data were collected from two sections of this course, the study's sample size was smaller than what would be necessary to conduct a full evaluation of the SALIANT. Second, the limited number of significant correlations with the SALIANT indicators highlights the need for further refinement and validation of this measure prior to data collection. Third, some of the SALIANT indicators were not directly applicable to the scenario chosen for this study, and, therefore, this limited the number of items evaluated for that category. This resulted in a restriction of range in the scores for these SALIANT categories, which, in turn, decreased the variability in the values. Future research is warranted to validate the SALIANT methodology with a larger sample size, scenarios with greater complexity, and an increased number of items for the SALIANT indicators. 


\section{Implications for Practice}

Given the high consequence for errors and the high cost of attrition, the issue of UAS operator selection and training has recently garnered considerable attention (e.g., Mirot, 2013; Pavlas et al., 2009). However, publication of definitive regulations regarding the qualification of UAS operators is warranted. Currently, one of the few established pilot qualification requirements regarding UAS is described within the 2008 Federal Aviation Administration's (FAA) Interim Operational Approval Guidance 08-01 in regard to civil use of UAS. This limited qualification requirement does not address the unique human performance challenges faced by UAS pilots. Once fully validated, the SALIANT methodology could allow for further development of qualification requirements and adequate training programs that cater to the specific needs of UAS operations under Title 14 of the Code of Federal Regulations (14 CFR) part 107. The SALIANT methodology could also aid in the evaluation of current training procedures and determine where changes can be made for improvement. Notably, a SALIANT checklist can be created for each training scenario and used as a debrief tool during an after-action review or as an instructional tool to enhance UAS curriculum.

Finally, the SALIANT methodology is ideally suited for critical assessment of SA within team settings (Milham et al., 2000). These assessments could be utilized to gain insights into current team SA behaviors and identify areas for improvement. In particular, findings from studies using the SALIANT methodology can be applied to create quality team-based training with a strong emphasis on improving team SA to promote safety and successful mission completion. 


\section{References}

Association for Unmanned Vehicle Systems International (AUVSI) (2013, March). The economic impact of unmanned aircraft systems integration in the United States (Economic Report). Retrieved from: http://www.auvsi.org/econreport

Blandford, A. \& Wong, W. (2004). Situation awareness in emergency medical dispatch. International Journal of Human-Computer Studies, 61, 421452. https://doi.org/10.1016/j.ijhcs.2003.12.012

Bolstad, C. A., Cuevas, H. M., Wang-Costello, J., Endsley, M. R., Angell, L. S. (2010). Measurement of situational awareness for automobile technologies of the future. In G.L. Rupp (Ed.), Performance metrics for assessing driver distraction: The quest for improved road safety (p. 195-216). Warrendale, PA: SAE International.

Breton, R., Tremblay, S., Bandbury, S. (2007). Measurement of individual and team situational awareness: A critical evaluation of the available metrics and tools and their applicability to command and control environments. Defense R\&D Canada- Valcartier Technical Report DRDC Valcartier TR 2003-283 May 2007.

Dalamagkidis, K., Valavanis, K. P., \& Piegl, L. A. (2008). On unmanned aircraft systems issues, challenges and operational restrictions preventing integration into the National Airspace System. Progress in Aerospace Sciences, 44 (7-8), 503-519. DOI: 10.1016/j.paerosci.2008.08.001

Endsley, M. R. \& Garland, D. J. (Eds.) (2000). Situation awareness analysis and measurement. Mahwah, NJ: Lawrence Erlbaum Associates.

Fern, L., Shively, R. J., Draper, M, H., Cooke, N. J., \& Miller, C. A. (2011). Human-automation challenges for the control of unmanned aerial systems. Proceedings of the Human Factors and Ergonomics Society 55th Annual Meeting (pp. 424-428). Santa Monica, CA: Human Factors and Ergonomics Society. DOI: 10.1177/1071181311551087

Fink, A. A., Major, D. A. (2000). Measuring team situation awareness: A comparison of three techniques. Paper presented at the Proceedings of the Fourth International Symposium on Aviation Psychology, Savannah, GA. 
Fiore, S. M., Fowlkes, J., Martin-Milham, L., \& Oser, R. L. (2000). Convergence or divergence of expert models: On the utility of knowledge structure assessment in training research. Proceedings of the XIVth Triennial Congress of the International Ergonomics Association and 44th Annual Meeting of the Human Factors and Ergonomic Society, 2, 427 - 430. Santa Monica, CA: HFES.

Flin, R. \& O'Connor, P. (2001). Applying crew resource management in offshore oil platforms. In E. Salas, C.A. Bowers, \& E. Edens (Eds.), Improving teamwork in organization: Applications of resource management training (pp. 217-233). Hillsdale, NJ: Erlbaum.

Fracker, M. L. (1991a). Measures of situation awareness: An experimental evaluation (Report No. AL-TR-1991-0127). Wright-Patterson Air Force Base, $\mathrm{OH}$ : Armstrong Laboratories.

Fracker, M. L. (1991b). Measures of situation awareness: Review and future directions (Report No. AL-TR-1991-0128). Wright-Patterson Air Force Base, OH: Armstrong Laboratories.

Gorman, J. C. Cooke, N. J., \& Winner, J. L. (2006). Measuring team situation awareness in decentralized command and control environments. Ergonomics, 49 (12-13), 1312-1325. DOI: 10.1080/00140130600612788

Milham, L. M., Barnett, J. S., \& Oser, R. L. (2000). Application of an event-based situation awareness methodology: Measuring situation awareness in an operational context. Proceedings of the XIVth Triennial Congress of the International Ergonomics Association and 44th Annual Meeting of the Human Factors and Ergonomics Society, 2, 423-426. Santa Monica, CA: HFES. https://doi.org/10.1177/154193120004401125

Mirot, A. (2013). The future of unmanned aircraft systems pilot qualification. Journal of Aviation/Aerospace Education \& Research, 22(3), 19-30. Retrieved from http://commons.erau.edu/jaaer/vol22/iss3/7

Muniz, E., Stout, R., Bowers, C., \& Salas, E. (1998). A methodology for measuring team situational awareness: Situated Linked Indicators Adapted to Novel Tasks (SALIANT). The First Annual Symposium/Business Meeting of the Human Factors \& Medicine Panel on Collaborative Crew Performance in Complex Systems, Edinburg, United Kingdom, 20-22 April 1998. Published in RTO MP-4. 
Nullmeyer, R. T., Stella, D., Montijo, G. A., \& Harden, S. W. (2005). Human factors in Air Force flight mishaps: Implications for change. Proceedings of the 27th Annual Interservice / Industry Training, Simulation, and Education Conference (paper no. 2260). Arlington, VA: National Training Systems Association.

Pavlas, D., Burke, S., Fiore, S. M., Salas, E., Jensen, R., \& Fu, D. (2009). Enhancing unmanned aerial system training: A taxonomy of knowledge, skills, attitudes, and methods. Proceedings of 53rd Annual Meeting of the Human Factors and Ergonomics Society (pp. 1903-1907). Santa Monica, CA: Human Factors and Ergonomics Society. DOI: $10.1518 / 107118109 X 12524444083159$

SESAR. (2012, October 22). Situational Awareness Linked Indicators Adapted to Novel Tasks (SALIANT). HP Repository. Retrieved from https://ext.eurocontrol.int/ehp/?q= node/1606

Stanton, N. A., Salmon, P. M., Walker, G. H., Salas, E. \& Hancock, P. A. (2017, February 6). State-of-science: Situation awareness in individuals, teams and systems. Ergonomics, 1-18. DOI: 10.1080/00140139.2017.1278796

Tvaryanas, A. P. (2006). Human systems integration in remotely piloted aircraft operations. Aviation Space and Environmental Medicine, 77 (12), 12781282. DOI: $10.1 .1 .628 .5468-1$

Williams, K. W. (2006). Human factors implications of unmanned aircraft accidents: Flight-control problems. Report Number DOT/FAA/AM-06/8. Washington, DC: Office of Aerospace Medicine. http://www.faa.gov/data_research/research/med_humanfacs/oamtechrepor ts/2000s/media /200608.pdf

Wills, C. (2011). The utility of unmanned combat air systems in gaining control of the air in future warfare in 2040: The importance of situational awareness. Journal of Battlefield Technology, 14(3), 11-17. 